\title{
Short-term flow dynamics of a retreating tidewater glacier: LeConte Glacier, Alaska, U.S.A.
}

\author{
S. O’Neel, K. A. Eghelmeyer, R. J. Motyka \\ Geophysical Institute, University of Alaska Fairbanks, Fairbanks, Alaska 99775-7230, U.S.A.
}

\begin{abstract}
An analysis of motion in the terminus region of LeConte Glacier, Alaska, U.S.A., delineates mechanisms that are important to tidewater glacier stability. This glacier is undergoing rapid retreat. Since 1995 it has retreated $2 \mathrm{~km}$ and thinned $>125 \mathrm{~m}$ at the present location of the terminus. Ice velocities in this region are quite high; at the terminus they exceed $27 \mathrm{~m} \mathrm{~d}^{-1}$. Our analysis reveals that fluctuations in speed and surface elevation are forced by ocean tides, surface melt and precipitation. The nearterminus ice speed is $180^{\circ}$ out of phase with the tide, such that high tide corresponds to low speed. Smaller, melt-forced diurnal variations in speed are present throughout the lowermost $7 \mathrm{~km}$. Speed-ups in excess of $10 \%$ of the mean often occur after rainstorms as a result of increased basal water pressure and storage, but the relation is not simple. The velocity does not vary over the spring and summer seasons.
\end{abstract}

\section{INTRODUCTION}

The concept of a tidewater glacier cycle is well established (Post, 1975), with many observations of tidewater glaciers that are either slowly advancing or rapidly retreating (e.g. Mercer, 1961; Meier and Post, 1987; Alley, 1991; Meier and others, 1994; Post and Motyka, 1995; Warren and others, 1995; Motyka and Begét, 1996). Rapid retreats are the result of an increased rate of calving, concurrent with a change in flow velocity. There is often an acceleration near the terminus, and heavy crevassing in the lower reaches. Speeds of $10-30 \mathrm{~m} \mathrm{~d}^{-1}$ are common. Additionally, retreating tidewater glaciers that terminate in deep water have termini that are highly buoyant, and basal motion dominates the flow in this region (Kamb and others, 1994; Meier and others, 1994). Knowledge of these near-terminus flow dynamics - including both rapid basal motion and iceberg calving - is essential to understanding tidewater glacier stability (e.g. Van der Veen, 1996).

Observations from Columbia Glacier, Alaska, U.S.A., indicate that after the initiation of the calving retreat in 1982, the ice velocity in the terminus region began to increase markedly (Krimmel and Vaughn, 1987; Meier and Post, 1987; Krimmel, 1997). Their detailed surveys of ice motion in the terminus region documented these trends and other variations in motion over multiple time-scales, and they investigated the role of ice motion in promoting calving and retreat. Both velocity and glacier length vary seasonally, with maximum length (in midJune) and minimum length (mid-September) lagging the maximum and minimum velocities, respectively, by 3 months (Krimmel, 1997). Walters and Dunlap (1987) and Walters (1989) describe short-term variations in motion, and relate these to changes in tidal stage and meltwater inputs. More recent field observations suggest that these short-term variations may be controlled by water storage at the bed (Fahnestock, 1991; Kamb and others, 1994, Meier and others, 1994).

LeConte Glacier is another rapidly retreating, grounded tidewater glacier. It is located in southeast Alaska, approxi- mately $35 \mathrm{~km}$ east of Petersburg (Fig. 1), and is the Northern Hemisphere's southernmost tidewater glacier. It mantles the Coast Range Batholith, a complex of resilient granodiorite. It is approximately $35 \mathrm{~km}$ long and has an area of $469 \mathrm{~km}^{2}$. Ice flows from a large accumulation area on the Stikine icefields (accumulation-area elevation range 2600-920 m; accumulation-area ratio $\approx 0.90$; Post and Motyka, 1995) into a deep, narrow fjord. In 1994, after a 32 year period of terminus stability, LeConte Glacier began a rapid retreat (personal communication from P. Bowen, 1999). Since then, it has retreated about $2 \mathrm{~km}$. Drastic thinning has accompanied the retreat, averaging $1.9 \mathrm{~m} \mathrm{a}^{-1}$ over the entire glacier from 1996 to 2000 , while at the present terminus position the glacier has thinned by about $125 \mathrm{~m}$ over the same 4 year period. At the terminus, calving activity is high: mass loss via calving is approximately 15 times the mass loss due to surface ablation.

Surface velocities near the terminus have been steadily increasing since our research began; they currently exceed 27 $\mathrm{m} \mathrm{d}^{-1}$. In this terminus region, velocities exhibit responses to multiple short-time-scale forcings, including semi-diurnal tides, diurnal variations in meltwater input and isolated precipitation events. In this paper we describe observations of these velocity variations and the separation of their signals via filtering and harmonic analysis. We then attempt to identify the underlying mechanisms causing these velocity variations. A companion paper that discusses our detailed observations of calving during the same period is in preparation.

\section{OBSERVATIONS}

\section{Bathymetry and surface features}

We used sonar sounding from a small boat to determine the bathymetry in the recently deglaciated fjord. Our data were quite dense in the near-terminus environment, and they show that the steep-walled fjord has a maximum depth of $\sim 270 \mathrm{~m}$ below sea level. A terminal moraine exists $2 \mathrm{~km}$ 

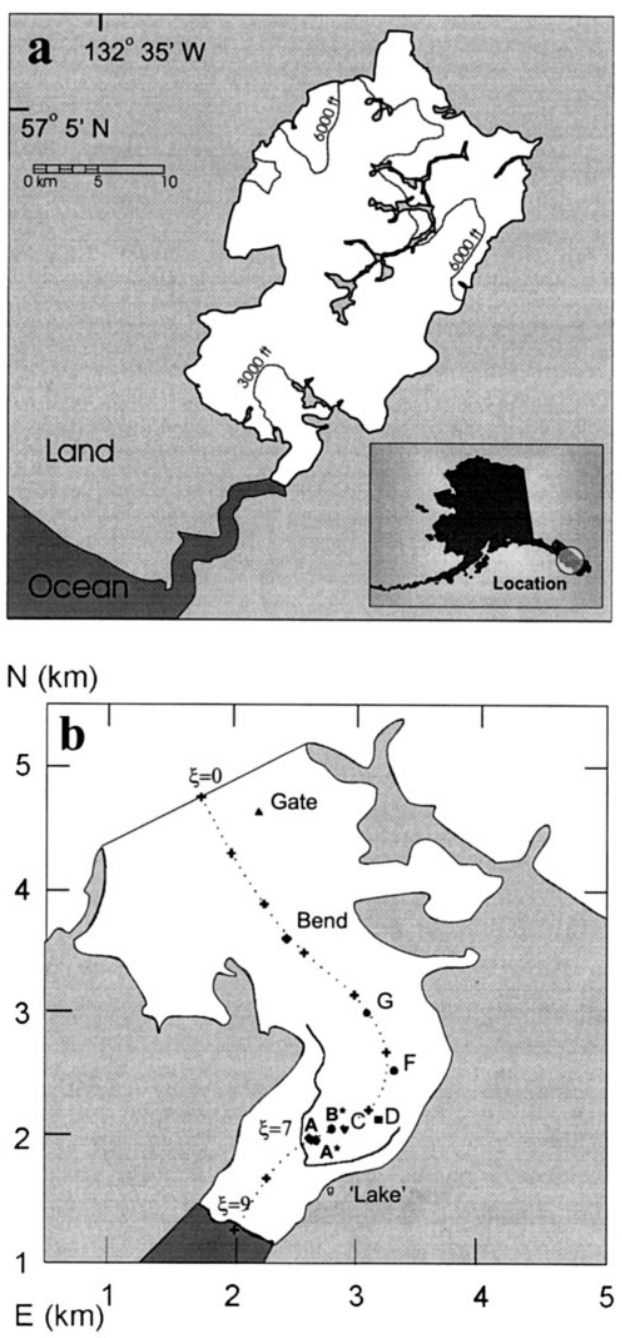

Fig.1. (a) Map of southeast Alaska showing location of LeConte Glacier. (b) Terminus region of LeConte Glacier, showing the longitudinal coordinate system $\{0: \xi: 9\}$, the 1994 terminus $(\xi=9)$, the May 1999 terminus (curve at $\xi=7)$, "Lake" camp, and center-line markers. Marker E was located between D and F for a short time only.

down-fjord of the present terminus, marking the most recent (1962-94) position of stability. There the water depth shallows to about $190 \mathrm{~m}$. Given the highly resistant surrounding bedrock, formation of such a submarine moraine is likely a much slower process than is typical for many other tidewater glaciers in Alaska, which generally erode soft sedimentary or metamorphic rocks (Hunter and others, 1996).

The terminus is completely grounded, but the majority of the terminal ice lies below sea level. With an average icecliff height of 40-60 $\mathrm{m}$ above the sea surface (as determined by helicopter-borne differential global positioning system (GPS) measurements and terrestrial surveying (accuracy $1-2 \mathrm{~m}$ )), the terminus is currently only $20-25 \mathrm{~m}$ above flotation. The glacier center line is shifted approximately $150 \mathrm{~m}$ south of the deepest part of the channel (Fig. 2a). The nearterminus surface topography is steep, with surface slopes on the order of $10^{\circ}$. Heavy crevassing dominates the lower $8 \mathrm{~km}$ of the glacier, with the last $4 \mathrm{~km}$ composed mainly of seracs and ice pinnacles.

\section{Motion}

Horizontal and vertical ice motion were monitored for 37 days (2 May-4 June and 26-30 August) at several markers. We used

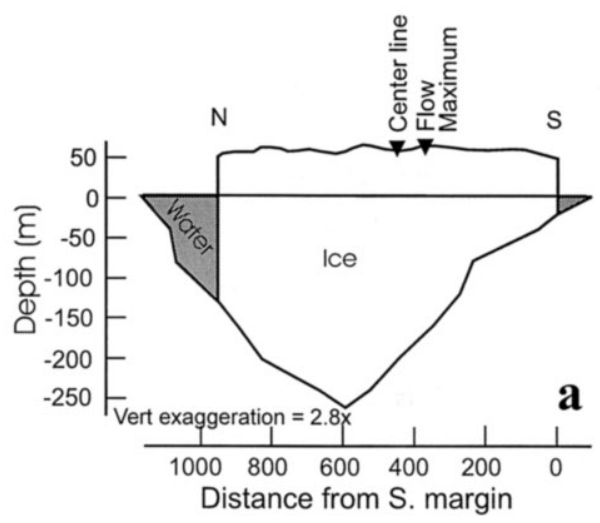

$\mathrm{N}(\mathrm{km})$

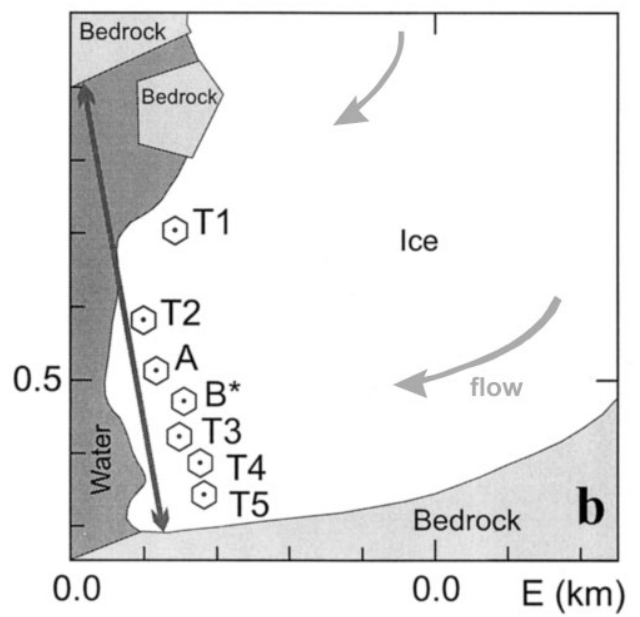

Fig. 2. (a) Glacier terminus and fjord bathymetry as measured in 1999, looking down-fjord. (b) Location of the transverse markers (hexagons). A gap exists between the ice and margin, as shown. The arrow marks the location of the cross-section shown in (a); asterisks denote replacement markers.

optical survey methods and tetrahedral markers placed on seracs. Over the course of the study, we deployed a total of 18 markers $0-7 \mathrm{~km}$ from the terminus. Thirteen of these markers were placed near the longitudinal center line of the glacier (labeled A-G, plus Bend and Gate in Fig. lb). The remaining five were set on a transverse profile across the width of the terminus (labeled T1-T5 in Fig. 2b); these were surveyed for only 2 days (Fig. 3). Due to serac instability and calving losses, some markers were periodically reset; new positions were chosen as close to the initial marker positions as possible in order to investigate the temporal changes in motion at a given point in space (i.e. within an Eulerian reference frame). Replacement markers are labeled with an asterisk (e.g. $\mathrm{B}^{*}$ ). A longitudinal coordinate system $\xi \in[0,9 \mathrm{~km}]$ was defined with the origin $(\xi=0)$ located just up-glacier from Gate (Fig. 1b), where the glacier enters a well-defined constriction, and is positive towards the terminus. $\xi=0$ is near the average 1990s equilibrium line, $\xi=7$ marks the May 1999 terminus position and $\xi=9$ the $1962-94$ position.

As we were interested in identifying any tidal forcing of glacier speed, we attempted motion surveys at intervals of a few hours in order to satisfy the Nyquist sampling criteria (a sampling interval less than or equal to $1 /$ (twice the frequency of interest); Godin, 1972). For a semi-diurnal cycle, this requires sampling at least four times per day. When possible, we surveyed at 2-3 hour intervals, with a 3-6 hour gap at night. Therefore, our surveys generally satisfy the sampling criteria, but the sampling interval was not constant and there were data gaps. 


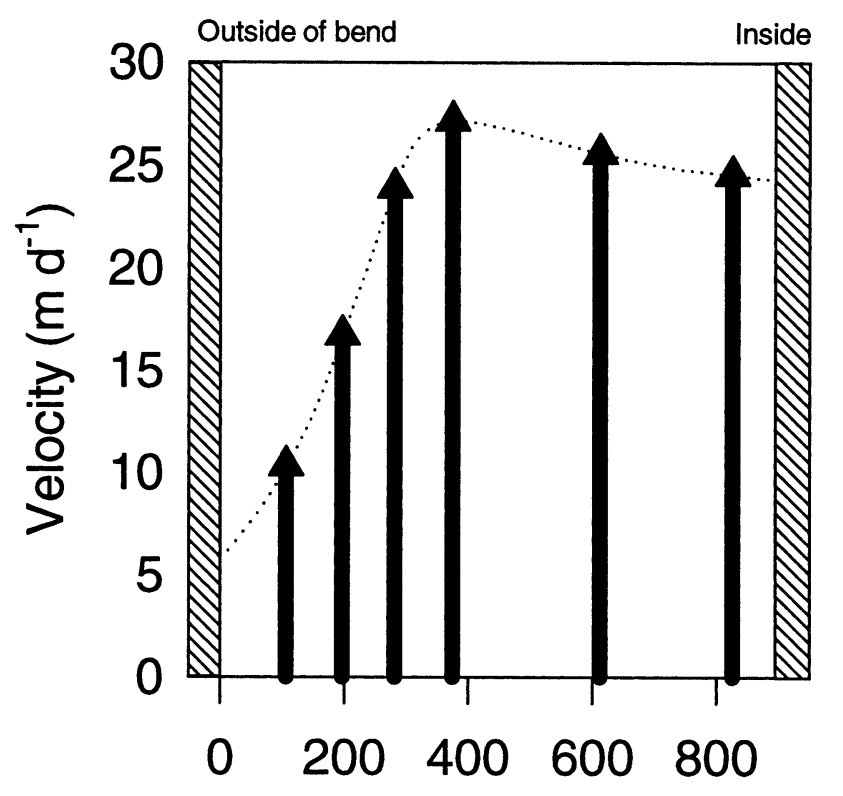

Distance from south margin $(\mathrm{m})$

Fig. 3. Transverse velocity profile at the terminus. The maximum ice velocity is shifted towards the outside of the bend by about $80 \mathrm{~m}$. Note that sliding occurs even at the margins.

The weather during May 1999 was unseasonably poor, and markers were sometimes obscured by clouds or precipitation during a survey. However, the resulting time series of motion are relatively complete, as can be seen in Figure 4 a. The estimated errors in the surveyed positions range from $\pm 3 \mathrm{~cm}$ in good conditions to $\pm 6 \mathrm{~cm}$ in poor surveying conditions. Over 3 hour time intervals these correspond to errors in velocity of \pm 0.34 and $\pm 0.68 \mathrm{~m} \mathrm{~d}^{-1}$, respectively. Additional errors were occasionally introduced by marker tilt or rotation. The average error in vertical position is estimated to be $\pm 5 \mathrm{~cm}$.

Further upstream at Bend and Gate (Fig. 1b), we deployed dual-frequency GPS receivers, with position data six and two times daily, respectively, for the duration of the study. Postprocessing of these data against a nearby base station ("Lake", Fig. lb) gave a positional accuracy of about $3 \mathrm{~cm}$; rotation of the markers as crevasses opened may have caused some degradation of this accuracy. A few gaps exist in this otherwise continuous record because of power losses.

\section{Tide}

Complete knowledge of the ocean tide at the glacier terminus is critical to our analyses of velocity and calving. The closest continuously operating tide gauge was located in Ketchikan, Alaska, $>100 \mathrm{~km}$ from the glacier. To more accurately determine the tide near the glacier we obtained U.S. National Oceanic and Atmospheric Administration (NOAA) waterlevel data collected in LeConte Bay during spring 1997 (http://www.co-ops.nos.noaa.gov/datares.html). We also installed our own tide gauge in the bay during August 1999. Using these data, we were able to prescribe the local tide at any time during our study, as described below. The tide in LeConte Bay (Fig. 4b) has a strong semi-diurnal component, with two highs and lows of unequal magnitude each day. Peak-to-peak amplitude varies from about 2.5 to $6 \mathrm{~m}$. In what follows we refer to the daily "tidal amplitude", which we define to be the range between the average of the two high tides and the two low tides each day.

\section{Other observations}

Hourly air temperature $\left( \pm 0.4^{\circ} \mathrm{C}\right)$ and ice ablation $( \pm 1 \mathrm{~cm})$ were measured using a thermistor probe, sonic ranger and data logger situated on a tributary glacier about $3 \mathrm{~km}$ from the terminus and $530 \mathrm{~m}$ a.s.l. The ablation rate (time derivative of the ablation data; Fig. 4c) exhibits clear diurnal variations, even though variable weather and long-duration rain events introduce large variability in the timing ( \pm 0.2 days $)$ and magnitude of the peak ablation rate. Thus the ablation rate has a broad spectral peak, centered around 1 cycle $^{-1}$. Negative values represent snowfall events.

Daily precipitation was measured by the U.S. National Weather Service at Petersburg Airport. We also measured precipitation for 9 days (days 145-154) at a temporary gauge near the terminus. The two records generally follow similar trends, but the magnitude of the precipitation at the glacier was often twice that measured in Petersburg (Fig. 4d). However, at times the precipitation differed markedly; the rain event recorded in Petersburg on day 151 occurred 1 day earlier at the terminus.

Water discharge from a tidewater glacier is difficult to monitor, but it plays an important role in basal hydrology and glacier motion. As a proxy for discharge, we made qualitative estimates of upwelling at the terminus by observing the timing and magnitude $(0-5)$ of silt-laden fresh-water plumes in the fjord, just downstream of the terminus (Fig. 4e). Upwelling plumes were easily recognizable as they would drive icebergs and brash ice away from the terminus, and a strong upwelling event (magnitude 5) would create whitecaps in the forebay. An absence of upwelling (magnitude 0) left the terminus region packed with ice.

\section{FEATURES OF THE MOTION}

Velocity data, with no smoothing, are presented in Figure 4a. Several features are noteworthy. First, the velocities of all markers are quite large, ranging from $\sim 10 \mathrm{~m} \mathrm{~d}^{-1}$ at $\xi=$ $4 \mathrm{~km}$ to $>27 \mathrm{~m} \mathrm{~d}^{-1}$ at the terminus. Second, a strong longitudinal velocity gradient is present; we attribute this to thickness gradients as ice flows to the terminus, as well as a substantial reduction in glacier width as the glacier is constrained by the valley walls. Third, semi-diurnal variations in surface velocity, with amplitudes up to $5 \%$ of the mean, are clearly visible for markers $\mathrm{A} / \mathrm{A}^{*}$ (where $\mathrm{A} / \mathrm{A}^{*}$ denotes the combined record for markers $\mathrm{A}$ and $\left.\mathrm{A}^{*}\right), \mathrm{B} / \mathrm{B}^{*}$ and $\mathrm{D}$. Nontidal diurnal variations in velocity with amplitudes up to $0.5 \mathrm{~m} \mathrm{~d}^{-1}(5-8 \%$ of mean $)$ are visible upstream from the terminus, especially at Bend and Gate. Fourth, a low-frequency variation, centered on day 145 and lasting about 3 days, is present in all velocity records. This event follows a period of heavy rain. Finally, there is an apparent temporal speedup, especially at markers A-C. However, this is simply a manifestation of marker motion within the large longitudinal velocity gradient present near the terminus.

To estimate the partitioning of the glacier flow mechanisms within the terminus region, we calculate the basal shear stress, $\tau_{\mathrm{b}}$, and the deformational velocity there. Because of the large longitudinal stress gradients that are present here, the calculations strongly depend on the length over which values of ice thickness and surface slope are averaged (Kamb 

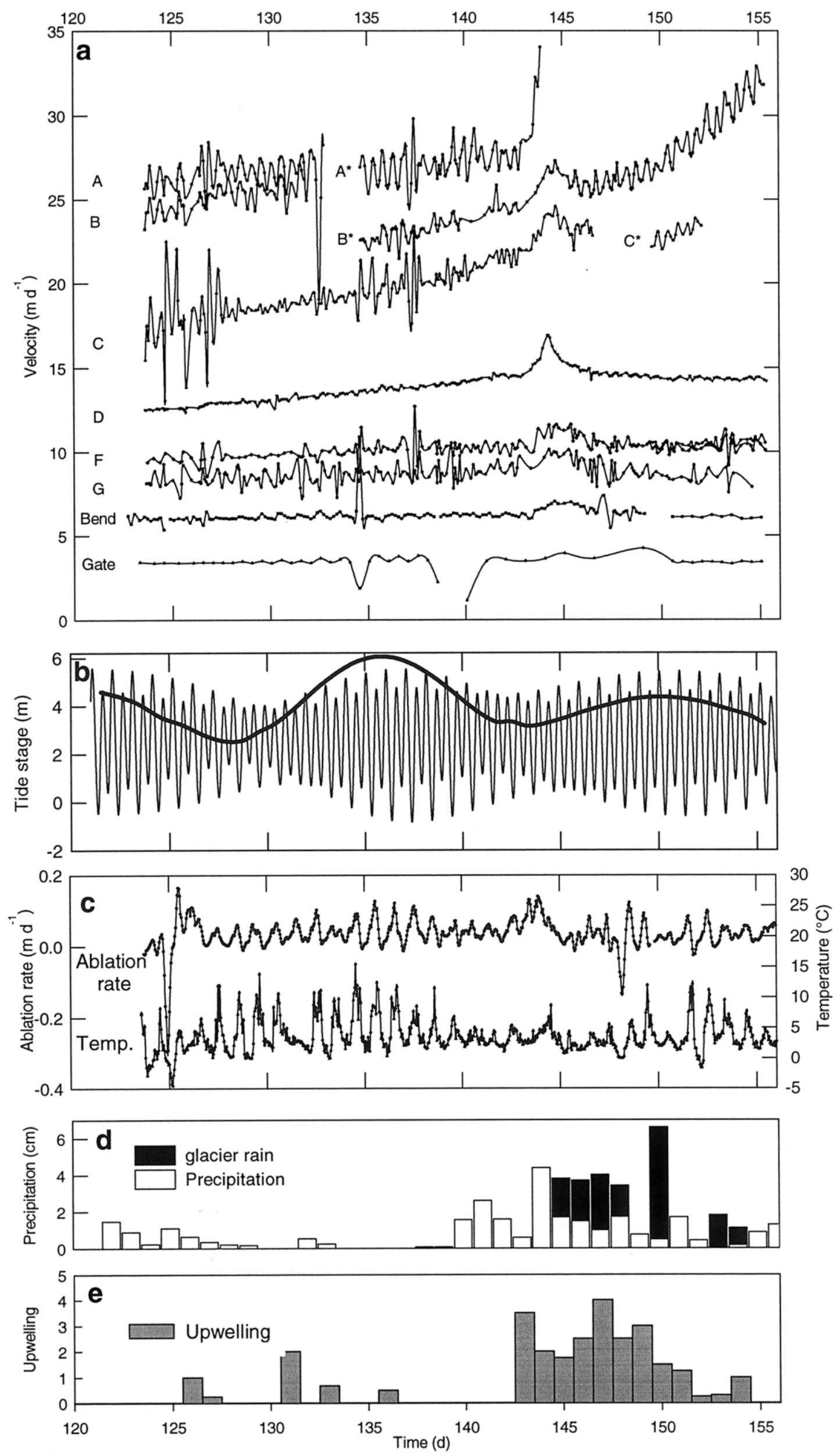

Fig. 4. (a) Velocity of each marker. (b) Predicted tide (thin line) and tidal amplitude (bold line). (c) Ablation rate and temperature as measured on an adjacent glacier. (d) Precipitation at Petersburg Airport, and, when available, local precipitation. (e) Upwelling at the terminus. 
and Echelmeyer, 1986). Given the extreme strain-rate conditions and the consequent uncertainty in this averaging length, we performed the analyses using a range of averaging lengths from 0.5 to $2.5 \mathrm{~km}$. We used the known bathymetry, an effective cliff height of $52 \mathrm{~m}$ (O'Neel, 2000), and assumed a horizontal bed to arrive at an average thickness of 375 $475 \mathrm{~m}$. The surface slope average varies between $8^{\circ}$ and $10^{\circ}$, and the appropriate shape factor is 0.53 . The calculated basal shear stresses are $2.1-2.8 \times 10^{5} \mathrm{~Pa}$, with a best estimate of $2.5 \times 10^{5} \mathrm{~Pa}$ as obtained using our preferred longitudinal coupling length of $0.5 \mathrm{~km}$ (or 1.2 times the near-terminus center-line thickness), as discussed below. Using typical flow-law parameters for temperate ice (Paterson, 1994) we find that internal deformation contributes only about $2 \mathrm{~m} \mathrm{~d}^{-1}$, or $8-20 \%$ of the observed surface velocity on the lower $3 \mathrm{~km}$ of the glacier. Thus we conclude that even though the driving stresses are quite large, the flow is dominated by basal motion. Observations also indicate that sliding occurs near the margins.

\section{Flow around a bend}

As ice approaches the terminus of LeConte Glacier, it flows around a sharp bend. There the center-line radius of curvature is about $1.1 \mathrm{~km}$, while the glacier is only $1 \mathrm{~km}$ wide. This causes a change in flow direction of $>90^{\circ}$ (Fig. lb). The transverse velocity profile near the end of this bend shows that the flow maximum is shifted outward by about $80 \mathrm{~m}$ from the glacier center line (Fig. 3). Theory describing ice flow in a curving channel (Echelmeyer and Kamb, 1987) accurately predicts this outward shift, but the details of the velocity profile and those of the theoretical one differ because basal (and marginal) motion dominates the actual flow. According to this theory, the surface slope should vary across the glacier, with maximum slope on the inside of the bend. Such a variation in slope is observed.

\section{Strain rate}

As ice approaches the terminus, it is subject to large longitudinal gradients in velocity (up to $6 \mathrm{a}^{-1}$ ) and in strain rate (Fig. 5). These strain rates are extremely large, being about an order of magnitude greater than those observed in the past on Columbia Glacier (Venteris and others, 1997). The strain rate reaches a maximum value about $200 \mathrm{~m}$ up-glacier from the terminus; it then drops an order of magnitude in the last $200 \mathrm{~m}$ to the terminus. This maximum occurs about one cross-sectional average ice thickness back from the terminus. These high strain rates cause heavy crevassing, as well as thinning in the terminus region. The recent thickness change at the terminus is known from repeat airborne profiles in 1996 and 2000; we estimate that thinning caused by longitudinal stretching alone is $19 \mathrm{~m} \mathrm{a}^{-1}$, or about $60 \%$ of the measured thinning rate. As noted above, the motion of the markers within such an extending flow regime leads to an apparent temporal increase in speed; this is a spatial rather than a temporal effect.

\section{Seasonal variations in speed}

Table 1 gives a comparison of velocity measurements made at similar locations on the glacier surface at different times of the year. These comparisons were made between markers that were located $<2 \mathrm{~m}$ apart along the flow direction to minimize errors due to the large longitudinal strain rates. The
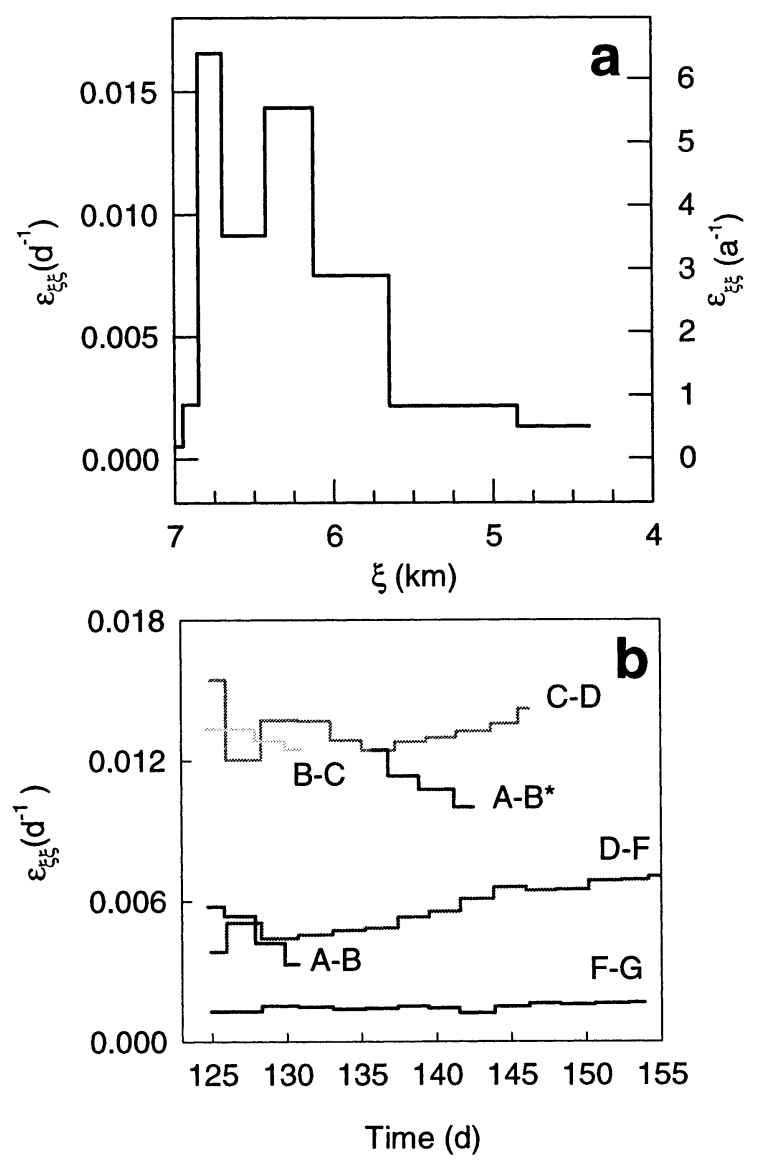

Fig. 5. (a) Longitudinal strain rate plotted as a function of $\xi$; extension is positive. (b) Longitudinal strain rate between markers as a function of time. At no time during the study was any part of the terminus region under longitudinal compression.

dates given in this table are the mid-times of the early-season velocity epoch (column 2) and of the later velocity epoch used in the comparison (column 4), while column 6 is the length of time over which the comparison is made. Columns 3 and 5 are the two velocities that are to be compared. The distances in the last column of Table 1 are the spatial separations of the markers between the two measurement epochs, as measured transverse to the flow direction. Large transverse separations in this column will introduce errors in our assumed temporal comparisons because of transverse variations in speed, but these are likely to be small as the flow is plug-like. Marker A shows no change in speed from pre-melt conditions (and no water input at the surface) into the early melt season. The other comparisons span a 3-4 month interval from early May to the end of August. The early part of this interval was

Table 1. Seasonal changes in speed. The velocities for markers moving along similar flowpaths at different times are shown. Marker separation distances are transverse to flow

\begin{tabular}{lccccrc}
\hline Marker & $\begin{array}{c}\text { Average } \\
\text { initial epoch } \\
\text { date }\end{array}$ & $\begin{array}{c}\text { Average } \\
\text { initial speed }\end{array}$ & $\begin{array}{c}\text { Average } \\
\text { final epoch } \\
\text { date }\end{array}$ & $\begin{array}{c}\text { Average } \\
\text { final speed }\end{array}$ & $\begin{array}{c}\text { Time } \\
\text { interval }\end{array}$ & $\begin{array}{c}\text { Marker } \\
\text { separation }\end{array}$ \\
& & $\mathrm{m} \mathrm{d}^{-1}$ & & $\mathrm{~m} \mathrm{~d}^{-1}$ & days & $\mathrm{m}$ \\
\hline $\mathrm{A}(7 \mathrm{~km})$ & 10 May & 26.7 & 17 May & 26.8 & 7 & 25 \\
$\mathrm{~B}(6.7 \mathrm{~km})$ & 9 May & 25.8 & 29 Aug. & 25.5 & 112 & 50 \\
$\mathrm{E}(5.5 \mathrm{~km})$ & 2 June & 10.7 & 28 Aug. & 13.7 & 86.5 & 445 \\
$\mathrm{G}(4.3 \mathrm{~km})$ & 27 May & 10.6 & 29 Aug. & 10.7 & 94 & 145
\end{tabular}




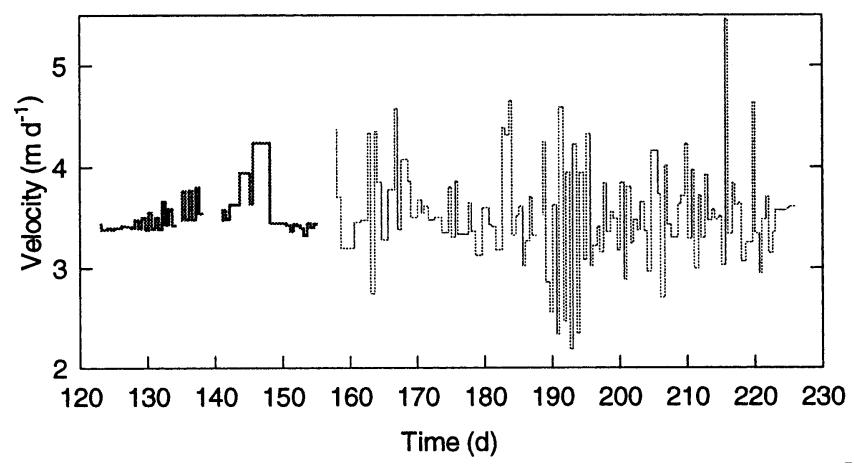

Fig. 6. Surface velocity at Gate. No seasonal changes are apparent.

characterized by precipitation as snow and little melt on the glacier; the middle spans the entire melt season; and at the end, new snow was accumulating on the glacier as low as Gate (700 m elevation). Over this interval, the glacier speed at these three locations was nearly constant; any differences are likely accounted for by the transverse position of the markers (especially marker E). Additional data come from the continuous GPS record obtained at Gate, which shows short-term variations but no seasonal change in speed over the same $>100$ day interval (Fig. 6). These results indicate that there is no change in speed over the lower $7 \mathrm{~km}$ of the glacier from late in the winter season through the entire melt season. Because this interval spans the transition from no surface input of water to the glacier system to a time of substantial water input, these results support the idea that there is little or no seasonal variation in speed on lower LeConte Glacier. Of course, it is possible to construct scenarios of summertime speed oscillations that would produce the observed lack of seasonal variation within our sampling scheme, but these scenarios are unrealistic.

\section{SHORT-TERM FLUGTUATIONS IN MOTION}

\section{Harmonic analysis of the tide}

The standard techniques of "harmonic analysis" (Godin, 1972; Foreman, 1993) were used to analyze the local tide and, subsequently, the ice-speed data. In this analysis we assume that a time series can be partially represented by a sum of discrete sinusoids, each with a prescribed frequency, $\omega_{i}\left(\mathrm{radh}^{-1}\right)$, as determined by tidal forces, but with unknown amplitude, $A_{i}$, and phase $\varphi_{i}$. That is:

$$
\mathcal{H}(t)=\sum_{i=1}^{N} A_{i} \cos \left(\omega_{i} t-\varphi_{i}\right)+M+\text { noise, }
$$

where $\mathcal{H}(t)$ is the tide (or later the ice speed), $t$ is the time in hours, $M$ is the mean of $\mathcal{H}(t)$, and the subscript $i$ ranges over the $N$ constituents assumed to make up the time series. Nonlinear least squares is then used to solve for the unknown amplitude and phase of each constituent. We also calculated the reduction of variance (ROV) in a stepwise fashion as each constituent is added to the analysis. This allows us to assess the relative strength of each constituent, and the chisquared test $\left(\chi^{2}\right)$ was used to determine the statistical significance of the predicted series. A residual time series, equal to the input series minus the $N$-component predicted series, was also calculated for later analyses.

The primary tidal constituents are either semi-diurnal or diurnal. Notation for these constituents consists of a letter representing the source (lunar, solar), followed by a sub- script delineating the approximate frequency per day (diurnal $=1$, semi-diurnal $=2$; Godin, 1972). For example, $M_{2}$ is the principal lunar semi-diurnal constituent.

We used the 1997 NOAA tide observations from LeConte Bay to solve for the amplitude and phase of the dominant tidal constituents. This solution was then checked against our 1999 tidal measurements, using a prediction via Equation (1). The six strongest constituents of the LeConte Bay tide are listed in order of decreasing importance in Table 2 . These constituents determined $\sim 98 \%$ of the variance in the tide signal. The semi-diurnal constituent $M_{2}$ dominates the tide $(81 \%$ ROV $)$, followed by the lunar diurnal constituent, $K_{1}$. The tide is relatively free of complicated shallow-water, overtide constituents at higher frequencies.

Using Equation (1) and the amplitude and phase for these six constituents, we can predict the tide at any time of interest, in particular during our survey in 1999 (Fig. 4b). The estimated accuracy is $0.25 \mathrm{~m}$, with few or no phase discrepancies, except during extremes in atmospheric pressure.

\section{Short-term variations in horizontal motion}

Here we describe the methods and results of our analyses of horizontal speed, $U(t)$, over tidal to several-day time periods.

\section{Signalfiltering}

Prior to the analysis, we detrended, smoothed and filtered the speed series displayed in Figure 4a. An Eulerian reference frame was approximated by removing the effects of the large longitudinal velocity gradients (Fig. 5). Cubic splines were fit to these data, and these were sampled at 3 hour intervals (our nominal surveying interval). These series were then subjected to a low-pass filter with a cut-off period of 24 hours in order to isolate that portion of the signal at lower than tidal frequencies. The filter used was $\mathcal{A}_{n}^{2} \mathcal{A}_{n+1}$, where

$$
\mathcal{A}_{n}=\frac{1}{n} \sum_{j=0}^{n-1} U(t+j \Delta t)
$$

(Godin 1972, p. 65). $U$ is the ice speed, $\Delta t$ is our sampling interval (3 hours), and $n=8$. Now isolated, the lowfrequency part of the signal was subtracted from the splined interpolant, leaving the high-frequency portion of the signal, $U_{\text {highfreq }}$.

$$
U_{\text {highfreq }}=U(t)-\mathcal{A}_{8}^{2} \mathcal{A}_{9}[U] .
$$

We describe the low- and high-frequency parts of the signal in turn.

\section{Low-frequency variations}

The low-frequency time series, $\mathcal{A}_{8}^{2} \mathcal{A}_{9}[U]$, for each marker

Table 2. LeConte Bay tide: tidal constituents (Godin, 1972), their periods and strength in the local tide

\begin{tabular}{ccc}
\hline Tidal constituent & Period & Variance reduction \\
& $\mathrm{h}$ & $\%$ \\
\hline$M_{2}$ & 12.421 & 81 \\
$K_{1}$ & 23.934 & 6.5 \\
$S_{2}$ & 12.000 & 6 \\
$L_{2}$ & 12.192 & 2 \\
$\mathcal{N}_{2}$ & 12.658 & 2 \\
$O_{1}$ & 25.819 & 1 \\
Total & & $\mathbf{9 8}$ \\
& &
\end{tabular}



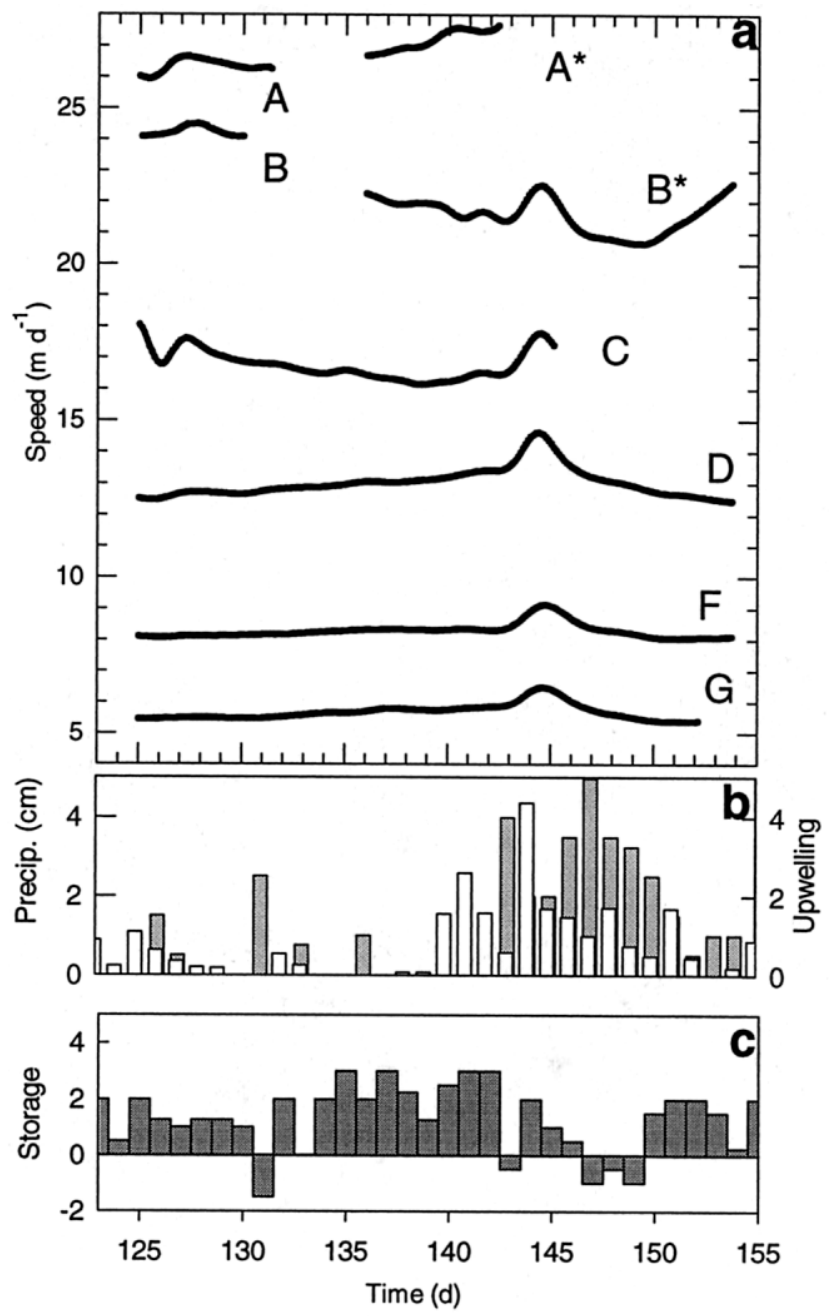

Fig. 7. (a) Low-frequency speeds for markers $A-G$; (b) precipitation (white) and upwelling (grey); and (c) a qualitative storage index.

are shown in Figure 7. The most prominent feature of these series is the speed-up event centered around day 144.5, which lasted about 3 days and had an amplitude of 5-13\% of the mean speed at each marker. The onset, duration, and time of peak speed are similar for each of the markers, with a variance of $<0.5$ day in their timing.

A correlation (correlation coefficient, $C=0.54-0.66$ ) with a phase lag of +1.0 day exists between the low-frequency speeds and excessive water input provided by heavy precipitation, such that precipitation events precede the maximum velocity. At some locations the speed decreased to a level that was lower than before the speed-up event (e.g. markers B* $, \mathrm{D}, \mathrm{G}$ ).

To investigate possible effects of water storage, we estimate a crude water-storage index (Fig. 8c). This index was compiled by differencing qualitative magnitudes of water

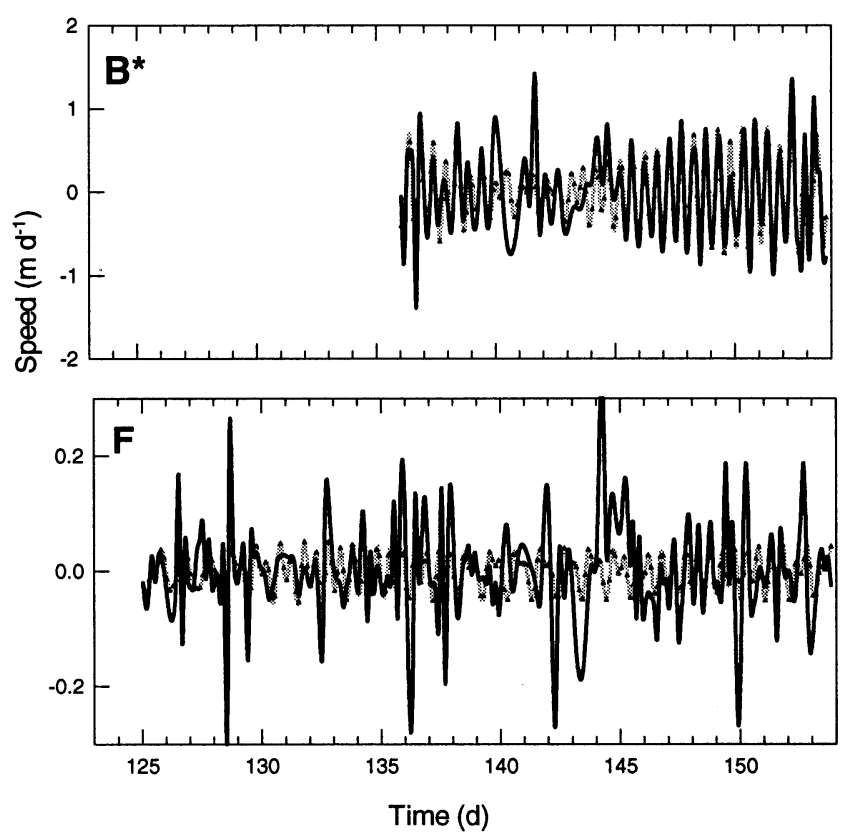

Fig. 8. Measured high-frequency horizontal speed (solid line) and the harmonic analysis prediction (dotted line and triangles).

input and output each day. Inputs and output were included in the index only when they were above "base" levels. Water input included any recorded precipitation and any surface melting in excess of the lowest maximum daily melt rate. Any observable upwelling (Fig. 8b) was considered to be above the base-level discharge. The velocity peak around day 144 is centered on an abrupt change in the water-storage index. However, the largest peaks in storage index did not coincide with velocity peaks.

\section{Semi-diurnal variations}

We applied harmonic analysis to the high-frequency time series,

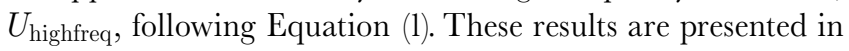
Table 3, where the total reduction of variance and the ROV for the semi-diurnal $M_{2}$ constituent alone are given, as well as the amplitude and phase for each constituent for each marker. Markers $\mathrm{A} / \mathrm{A}^{*}$ and $\mathrm{B}^{*}$ demonstrate the best overall ROV, and there is an approximate up-glacier decay in the overall ROV. Near the terminus $\left(\mathrm{B}^{*}\right.$, Fig. 8), the predicted series matches the observations quite well $\left(\chi^{2}\right.$ for markers $\mathrm{A} / \mathrm{A}^{*}$ and $\mathrm{B}^{*}$ yields $<1 \%$ probability of a random fit). Even in these cases, however, the ROV is $<50 \%$, indicating that the velocity fluctuations are not completely tidal in nature. The upstream markers have a poorer fit (e.g. F in Fig. 8; see also O’Neel, 2000), and the probability of a random fit is on the order of $50 \%$. Marker $\mathrm{C}$ has an abnormally noisy record.

The results in Table 3 show that, as in the case of the tide,

Table 3. Harmonic analysis of horizontal velocity: amplitude $(A)$ and phase $(\varphi)$ relations for each marker and the tide using the six strongest tidal constituents. The total ROVand the $M_{2}$ ROV are given in parentheses

\begin{tabular}{|c|c|c|c|c|c|c|c|c|c|c|c|c|c|c|}
\hline \multirow{2}{*}{$\begin{array}{c}\text { Tidal } \\
\text { constituent }\end{array}$} & \multicolumn{2}{|c|}{ Tide $(98 \% / 81 \%)$} & \multicolumn{2}{|c|}{$A / A^{*}(45 \% / 35 \%)$} & \multicolumn{2}{|c|}{$B^{*}(56 \% / 41 \%)$} & \multicolumn{2}{|c|}{$C / C^{*}(6 \% / 2 \%)$} & \multicolumn{2}{|c|}{$D(10 \% / 6 \%)$} & \multicolumn{2}{|c|}{$F(10 \% / 3 \%)$} & \multicolumn{2}{|c|}{$G(11 \% /<1 \%)$} \\
\hline & A & $\varphi$ & A & $\varphi$ & A & $\varphi$ & A & $\varphi$ & $A$ & $\varphi$ & $A$ & $\varphi$ & A & $\varphi$ \\
\hline$K_{1}$ & 0.561 & 131 & 0.219 & -32 & 0.092 & -94 & 0.110 & -168 & 0.004 & -33 & 0.017 & 53 & 0.039 & 79 \\
\hline$S_{2}$ & 0.511 & 75 & 0.118 & -96 & 0.231 & -148 & 0.015 & 15 & 0.030 & -144 & 0.015 & -168 & 0.025 & -167 \\
\hline$L_{2}$ & 0.357 & 133 & 0.150 & 147 & 0.036 & 121 & 0.095 & 21 & 0.008 & 6 & 0.014 & -128 & 0.01 & 93 \\
\hline$N_{2}$ & 0.342 & 41 & 0.242 & -110 & 0.129 & -28 & 0.120 & -143 & 0.015 & 167 & 0.007 & -68 & 0.018 & 176 \\
\hline$O_{1}$ & 0.247 & 108 & 0.109 & -175 & 0.066 & -174 & 0.176 & 166 & 0.023 & 125 & 0.016 & -46 & 0.017 & -131 \\
\hline
\end{tabular}


most of the speed fluctuations are semi-diurnal $\left(M_{2}\right)$. The other constituents in the speed are poorly resolved, as their signal is either too weak or contaminated by other forcings (also noted on Columbia Glacier by Walters and Dunlap, 1987). Such contamination from non-tidal forcings is illustrated by abrupt changes in phase between constituents of similar frequency (Table 3), rather than a smooth response (Zettler and Munk, 1975). We therefore take the $M_{2}$ response given in Table 3 to represent the effects of the tide on velocity at each marker.

The $M_{2}$ phase angle for the tide is $16^{\circ}$, and the average $M_{2}$ phase angle for markers $\mathrm{A} / \mathrm{A}^{*}$ and $\mathrm{B}^{*}$ is about $-160^{\circ}$. Thus, the phase difference between the two is $176^{\circ}$. Minimum speed occurs at peak tide, with virtually no phase lag.

Statistical analysis shows that the amplitude of $M_{2}$ given in Table 3 is well resolved. It thus provides a means for studying the up-glacier propagation of tidal forcing through its amplitude admittance. We define the $M_{2}$ admittance, $\Lambda_{M_{2}}$ as the ratio of the amplitude of the $M_{2}$ speed variation to the amplitude of $M_{2}$ in the tide:

$$
\Lambda_{M_{2}}=\frac{A_{M_{2}}^{\text {ice }}}{A_{M_{2}}^{\text {tide }}} .
$$

There is an exponential decay in $\Lambda_{M_{2}}$ with distance upglacier from the terminus (Fig. 9). This decay has a characteristic damping length (damping to $1 / e$ of peak value) equal to $0.5 \mathrm{~km}$, or about 1.2 times the center-line ice thickness at the terminus.

\section{Diurnal variations}

Diurnal cycles exist in both temperature and ablation rate. These cycles likely influence water input to the glacier system, and therefore may affect glacier speed. However, resolving such forcing is difficult because the tide also contains some diurnal constituents, albeit with low energy. Separation is especially difficult because of the broad width of the diurnal melt peak, which is indicative of variable weather conditions.

In an effort to separate these two signals, we assume that $U_{\text {highfreq }}$ is a linear combination of two terms: $U_{\text {tide, which }}$ accounts for motion driven by the tide, and $U_{\text {melt }}$, which represents meltwater-forced motion plus noise. Then

$$
U_{\text {highfreq }}=U_{\text {tide }}+U_{\text {melt }} \text {. }
$$

We then assume that $U_{\text {tide }}$ can be prescribed by the $M_{2}$ admittance as applied to the other constituents by an admittance transfer function:

$$
U_{\text {tide }}=\sum_{i=1}^{6} \Lambda_{M_{2}} A_{i}^{\text {tide }} \cos \left(\omega_{i} t-\varphi_{i}^{\exp }\right) .
$$

Here $\varphi_{i}^{\exp }$ is the expected phase angle for the $i$ th constituent, obtained by shifting the $i$ th tidal phase by $176^{\circ}$, as found for $M_{2}$. Thus, we assume that the relative admittance of each of the six constituents is equal to the well-resolved $M_{2}$ admittance. Tests with synthetic data have shown that this admittance transfer function (Equation (6)) is effective for separating a melt signal from a tidal one (O’Neel, 2000).

Following Equation (5), this admittance transfer function was subtracted from the high-frequency time series to obtain $U_{\text {melt }}$. These results show that melt-driven variations in horizontal motion are best developed upstream at markers D through Bend (Fig. 9; O’Neel, 2000), but they exist to some degree at most markers.

The average amplitudes of the melt-forced variations in speed were estimated for each $U_{\text {melt }}$ series. A step change in

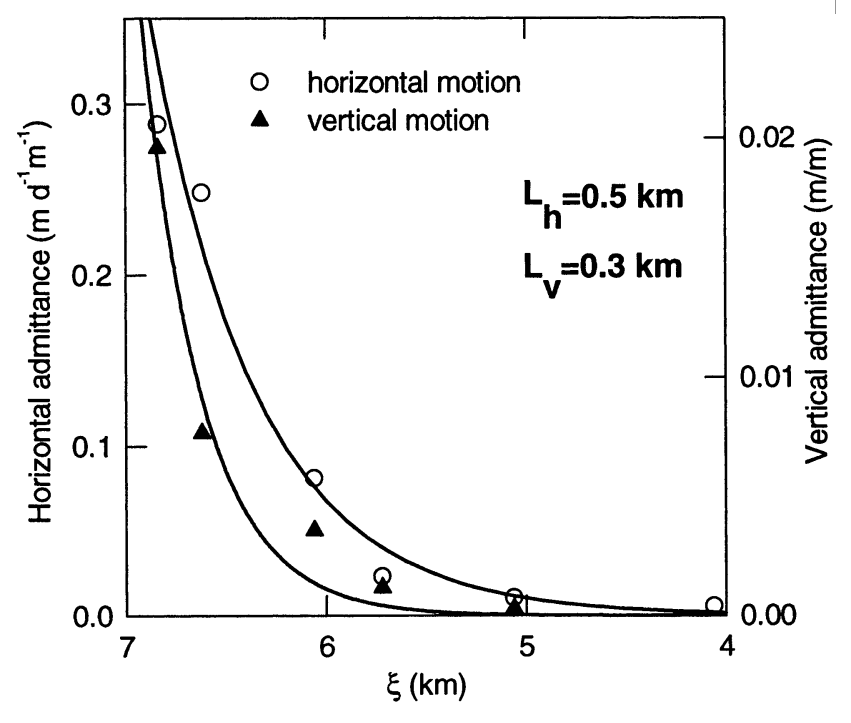

Fig. 9. Horizontal and vertical $M_{2}$ admittances (circles and triangles, respectively).

the peak-to-peak amplitude occurs between markers $\mathrm{C}$ and $\mathrm{D}$; A-C have amplitudes of $\sim 50 \mathrm{~cm} \mathrm{~d}^{-1}$, while markers upstream have smaller amplitude variations of only $\sim 20 \mathrm{~cm} \mathrm{~d}^{-1}$. However, the upper markers have less "noise" due to tidal forcing, so diurnal fluctuations are better resolved there.

We used cross-correlation to identify the lag between surface ablation and ice speed. In all cases, the ablation-rate peaks precede increases in speed (Table 4). The statistical significance of the correlations was small when calculated over the entire interval; this indicates that the phase lag between the two variables is not constant. However, by splitting the time series into two intervals (days 124-135 and 135-154), the correlations between the variables for each interval and for each marker are greatly improved (Table 4). Day 135 thus marks a change in the response time of the speed to melt forcing; the average response time is reduced from 23 hours to 10 hours. Prior to day 135, the phase lag generally increases up-glacier, but after day 135 it is more variable, exhibiting no obvious trends.

\section{Short-term variations in vertical motion}

We next consider the vertical position, $z(t)$, of each marker over the same time-scales as those discussed for horizontal speed, using the same analysis methods. For each marker,

\begin{tabular}{|c|c|c|c|c|c|c|}
\hline \multirow{3}{*}{$\begin{array}{l}\text { Markers and } \\
\text { observation dates }\end{array}$} & \multicolumn{2}{|c|}{ Total record } & \multicolumn{2}{|c|}{ J.D. $<135$} & \multicolumn{2}{|c|}{ J.D. $>135$} \\
\hline & Phase lag & $C$ & Phase lag & $C$ & Phase lag & $C$ \\
\hline & $\mathrm{h}$ & & $\mathrm{h}$ & & $\mathrm{h}$ & \\
\hline $\mathrm{A} / \mathrm{A}^{*}(124-130)(135-143)$ & NA & NA & 21 & 0.73 & 6 & 0.52 \\
\hline $\mathrm{B} / \mathrm{B}^{*}(124-129)(135-154)$ & NA & NA & 21 & 0.57 & 15 & 0.30 \\
\hline C $(124-146)$ & 21 & 0.49 & 21 & 0.65 & 9 & 0.41 \\
\hline $\mathrm{D}(125-154)$ & 12 & 0.22 & 21 & 0.32 & 9 & 0.34 \\
\hline $\mathrm{F}\left(125^{-153)}\right.$ & 3 & 0.21 & 9 & 0.20 & 6 & 0.34 \\
\hline $\mathrm{G}(125-152)$ & 9 & 0.2 & 12 & 0.13 & 9 & 0.28 \\
\hline Bend (128-144) & 21 & 0.1 & 24 & 0.61 & 15 & 0.35 \\
\hline
\end{tabular}

Table 4. Cross-correlation (correlation coefficient $C$ ) between $U_{\text {melt }}$ and ablation rate

Notes: The analysis was performed over the entire record, and again with a split on day 135 when an apparent change in the subglacial hydraulics took place. J.D., Julian day; NA, not applicable. 

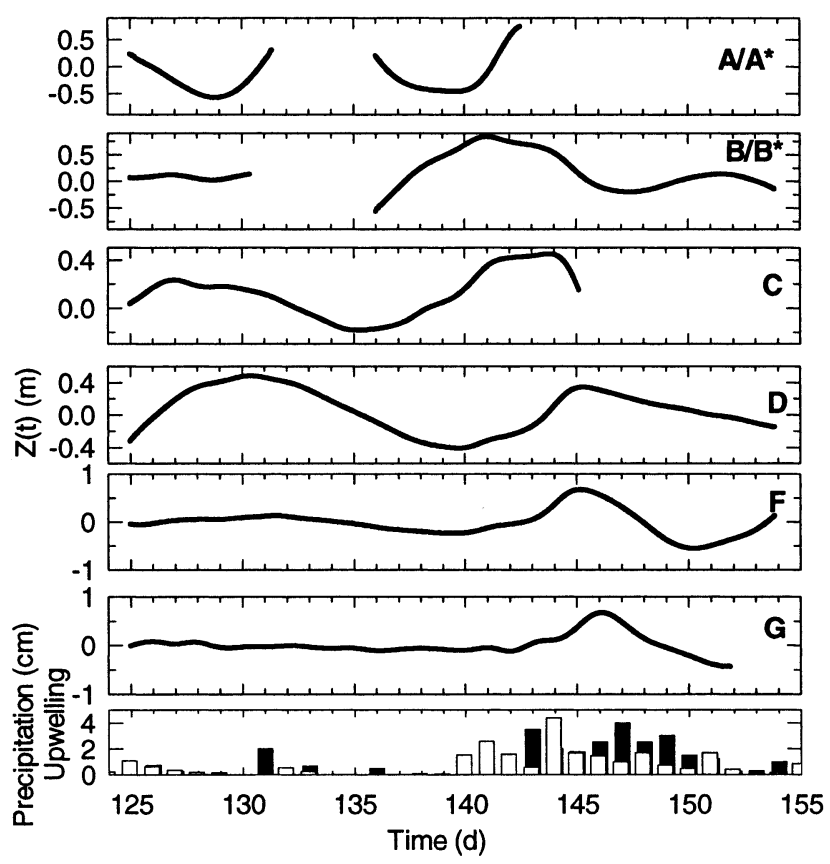

Fig. 10. Low-frequency vertical position for each marker. Precipitation (white) and upwelling (black) are shown in lower panel.

downslope movement was removed by subtracting a quadratic representation of the local glacier surface from the $z(t)$ series, as determined by airborne surface profiling.

\section{Low-frequency vertical variations}

The low-frequency vertical displacement signals (Fig. 10) do not show a consistent pattern at the different markers; some of this may be due to the detrending applied to the data. The upstream markers (D, F, G) show an uplift event centered on about day 145 corresponding to the precipitation-related speed-up event shown in Figure 7; this is not observed at the near-terminus markers. After heavy rain, the glacier surface at $\mathrm{D}-\mathrm{G}$ is uplifted; it then drops upon the initiation of upwelling. There was no longitudinal compression during these vertical motion events.

Fluctuations in vertical position at marker $\mathrm{A} / \mathrm{A}^{*}$ are approximately in phase with the tidal amplitude; minimum surface elevation coincides with minimum tidal amplitude. Vertical motion at markers $\mathrm{B}$ and $\mathrm{C}$ shows no correlation with either the tidal amplitude or precipitation.

\section{High-frequency vertical variations}

Harmonic analysis of $z_{\text {highfreq }}(t)$ shows that semi-diurnal tidal forcing of surface elevation exists only at the markers closest to the terminus (e.g. A/A*, Fig. 11). However, even though this figure appears to show a strong semi-diurnal signal at $\mathrm{A} / \mathrm{A}^{*}$, the ROV for the $M_{2}$ component is small there, and even smaller for $\mathrm{B}^{*}$ (Table 5 ). The peak-to-peak amplitude of the $M_{2}$ variation at $\mathrm{A} / \mathrm{A}^{*}$ is on the order of $13-18 \mathrm{~cm}$, with a phase lag of about $90^{\circ}$, such that the maximum surface elevation follows the high tide by $\sim 3$ hours. This implies that the maximum uplift rate $(\mathrm{d} z / \mathrm{d} t)$ occurs at high tide. The upglacier decay of the semi-diurnal fluctuations in $z$ is more rapid than the horizontal $M_{2}$ motion $\left(L_{\mathrm{v}}=0.3 \mathrm{~km}\right.$; Fig. 9). Because the semi-diurnal tidal constituent $M_{2}$ does not dominate the signal, the admittance transfer function (Equation (6)) cannot be applied to further analysis of $z(t)$.

For the vertical position of markers $\mathrm{A}-\mathrm{F}$ the variance

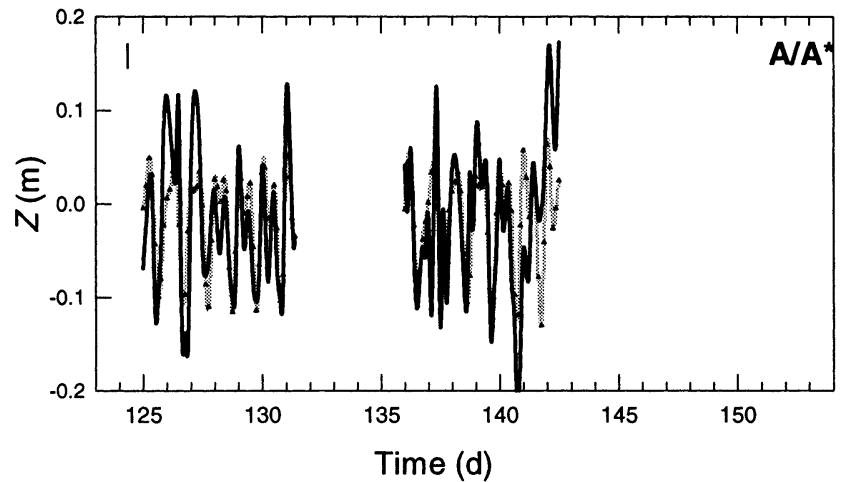

Fig. 11. $z_{\text {highfreq }}$ for marker $A / A^{*}$ ( solid line) and the harmonic analysis prediction (dotted line and triangles). A typical error bar is shown in the upper left. This semi-diurnal forcing exists only near the terminus and is rapidly damped up-glacier.

reduction due to the diurnal constituents $K_{1}$ and $O_{1}$ is significantly greater than the ROV in the tide for these same constituents (Table 5). The peak-to-peak amplitude of these diurnal variations is fairly constant $(8-12 \mathrm{~cm})$ between the markers, which we feel is above our level of measurement uncertainty. These results suggest that the diurnal fluctuations in uplift are related to diurnal meltwater production, and not $K_{1}$ and $O_{1}$ tidal forcing.

\section{DISGUSSION}

Here we present a discussion of the observed fluctuations in motion in terms of the flow mechanisms and dynamics of LeConte Glacier. The discussion considers only the terminal reaches $(0<\xi<7)$; it does not apply to the upper glacier where different processes may be controlling the dynamics.

In some cases, similar studies have been completed on Columbia Glacier, so we can directly compare our results with those found there. We note that the two glaciers are located in a similar maritime climate, but LeConte is only about half the size of Columbia Glacier. Also, the small surface slope and broad terminus of Columbia Glacier contrast with the steep, narrow snout of LeConte. Both glaciers are retreating, both show rapid motion near the terminus, and on both the velocities are dominated by basal motion.

\section{Semi-diurnal variations}

Ice speed on LeConte Glacier is $180^{\circ}$ out of phase from the tidal stage. A $1.5 \%$ variation in sea level $(\sim 3.0 \mathrm{~m}$ of $171 \mathrm{~m}$ mean depth) causes a $5.5 \%$ fluctuation in speed $(\sim 1.5$ out of $27 \mathrm{~m} \mathrm{~d}^{-1}$ mean speed, marker A/A*). Equivalently, this may

Table 5. Harmonic analysis of vertical position. The variance reduction is shown for the $M_{2}$ constituent, as well as the combined reduction for diurnal constituents $K_{1}$ and $O_{1}$

\begin{tabular}{lcc}
\hline Marker & Diurnal $\left(K_{1}, O_{1}\right)$ ROV & $\begin{array}{c}\text { Semi-diurnal }\left(M_{2}\right) \text { ROV } \\
\%\end{array}$ \\
& $\%$ & \\
\hline Tide & 7.5 & 81 \\
A/A* & 28 & 9 \\
B/B & 31 & 4 \\
G & 22 & 1 \\
D & 17 & 0 \\
$\mathrm{~F}$ & 21 & 0 \\
G & 6 & 1 \\
\hline
\end{tabular}


be expressed as $0.5 \mathrm{~m} \mathrm{~d}^{-1}$ per $\mathrm{m}$ of tide. On Columbia Glacier, Meier and Post (1987) reported a $4 \%$ variation in speed caused by a $1 \%$ fluctuation in tide, or $0.2 \mathrm{~m} \mathrm{~d}^{-1}$ per $\mathrm{m}$ of tide. Walters and Dunlap (1987) also found that the speed at Columbia Glacier was nearly $180^{\circ}$ out of phase with the tide.

The similarity between the magnitude and phase of tidal forcing on the two glaciers suggests that semi-diurnal variations in velocity are governed by the amplitude of the tidal fluctuations regardless of terminus geometry (slope, thickness, water depth), as long as the terminus is not floating. (On the floating terminus of Jakobshavn Isbræ, Greenland, the speed is a maximum when the tide is rising fastest $(\mathrm{K}$. A. Echelmeyer, unpublished data)). These semi-diurnal variations may be explained by a time-varying hydrostatic force imbalance at the terminus (Walters and Dunlap, 1987; Walters, 1989), where the water column acts as a dam with a time-dependent height. This leads to longitudinal stress gradients that vary with the tide. Maximum restraint occurs at high tide, leading to minimum speed. The variations in speed further depend on the daily tidal range, being best developed when the tidal amplitude is maximum (Fig. 4). Note that if, instead, the tide were to cause a time-varying pressurization of the hydraulic system, and a consequent change in basal motion, as predicted by typical sliding "laws", then one would expect zero lag between the tide and speed at the terminus. Similarly, if high tide were to cause decreased water discharge from the glacier - and thus increased water storage - then one might again expect zero lag between glacier speed and the tide, as increased storage would be expected to decrease basal drag and increase glacier motion.

The exponential decay length for the semi-diurnal perturbations serves as a proxy for the length over which longitudinal stress gradients are averaged in this region of the glacier (Echelmeyer, 1983; Kamb and Echelmeyer, 1986; Walters, 1989). This decay length is much smaller than the $2 \mathrm{~km} e$-folding length at Columbia Glacier, especially when compared to near-terminus ice thickness, which is only slightly larger on Columbia Glacier. The short coupling length on LeConte Glacier ( $\sim$ ice thickness) can be attributed to the extreme longitudinal strain-rate gradients found there (Fig. 5), following the theory of Kamb and Echelmeyer (1986). At the time of Walters and Dunlap's (1987) observations, the near-terminus strain rates on Columbia Glacier were $0.2-0.3 \mathrm{a}^{-1}$, or almost 20 times smaller than those on LeConte Glacier. In that case, one would expect a coupling length of about four times the center-line thickness, as observed. However, the large contribution of basal motion at LeConte Glacier generally exceeds the assumptions used in the Kamb and Echelmeyer model, so the agreement cannot be expected to be exact.

We also observed semi-diurnal variations in surface elevation at the terminus, with the maximum rate of uplift occurring at high tide. These variations in surface elevation are not caused by longitudinal compression (Fig. 5). Neither are they caused by extensional thinning due to the larger magnitude of the tidal speed changes at $\mathrm{A} / \mathrm{A}^{*}$ than at $\mathrm{B} / \mathrm{B}^{*}$ (Figs 4 and 12); this would be in phase with the horizontal speed. This suggests that the water column not only acts as a dam, but also affects subglacial water storage or pressure, leading to uplift. These apparently contradictory observations may possibly be explained by considering the overall longitudinal force balance near the terminus. The large basal velocities indicate that overall basal drag is small. This, combined with the shape of the transverse velocity profile (Fig. 3), indicates that marginal drag is the main source of restraint in
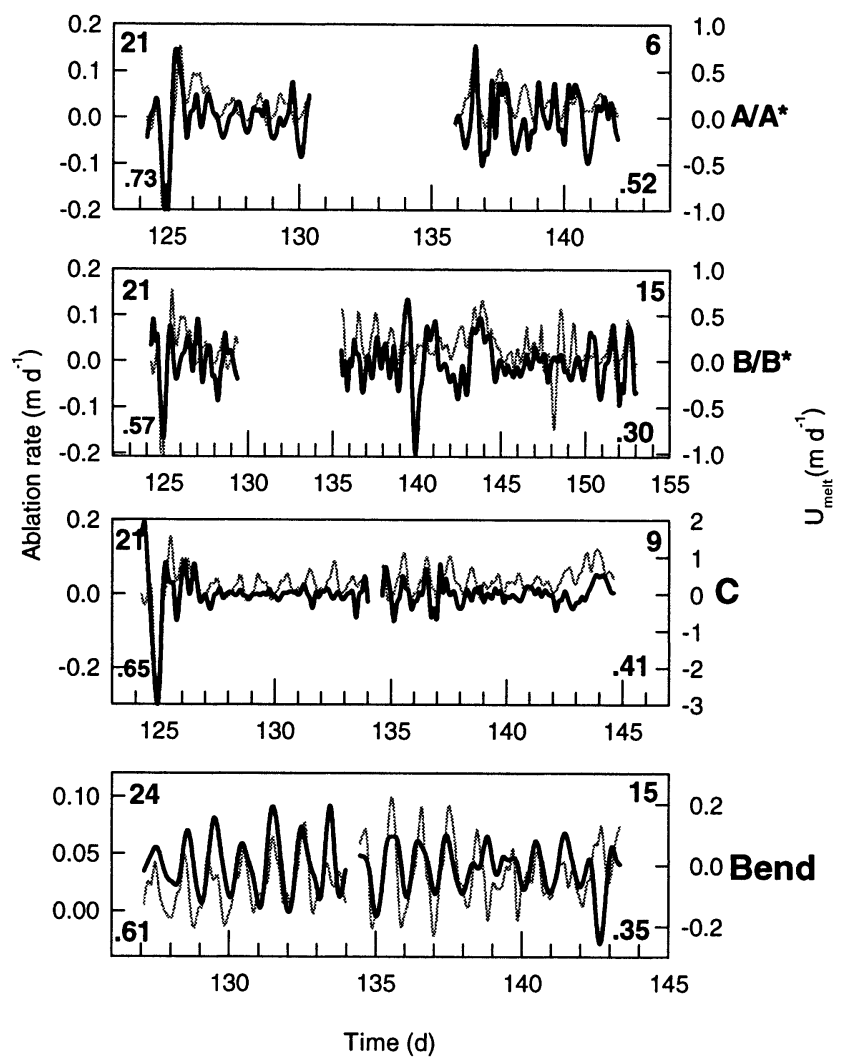

Fig. 12. Meltwater-forced variations in ice velocity. Ablation rate is plotted with a thin line (scale changes between plots), and the 6 hour running mean $U_{\text {melt }}$ series are shown with a bold line. The time series of motion have been phase-shifted for maximum correlation with ablation rate, and there is a change in lag on day 135. Lags (in hours) are provided in the upper corners, and the correlation coefficient is shown in the lower corners, for both the early and late parts of the records.

this near-terminus regime. Superimposed on this large marginal drag are small tidal variations in longitudinal back pressure (i.e. longitudinal stress gradients). These changing longitudinal stress gradients are large enough to affect the horizontal speed. But, because basal drag is already small, the small perturbations in effective pressure caused by a $\sim 1 \%$ change in water level ( $3 \mathrm{~m}$ tide/250 $\mathrm{m}$ water depth) are insufficient to cause much of an overall change in basal motion. On the other hand, the rapid up-glacier decay of semi-diurnal vertical variations $\left(L_{\mathrm{v}}=0.3 \mathrm{~km}\right.$; Fig. 9), plus the near-hydrostatic ratio of the effective glacier thickness (thickness corrected for crevasse void space) to water depth, imply that the terminus must be grounded but quite near flotation, and that this region of near-flotation exists only within $\sim 300 \mathrm{~m}$ of the terminus. Because the terminus is near flotation, a $\sim 1 \%$ change in water depth can cause a change in basal water storage or pressure that is sufficient to cause local uplift but does not cause any perceptible change in speed via "typical" sliding ideas.

\section{Diurnal variations}

The observed tide at LeConte Glacier has little energy at diurnal frequencies, but diurnal variations in speed are observed over the entire terminus region (Fig. 12). The amplitudes of these speed variations range from $10 \mathrm{~cm} \mathrm{~d}^{-1}$, or $\sim 5 \%$ of the mean speed, at up-glacier locations such as Bend and Gate, to $70 \mathrm{~cm} \mathrm{~d}^{-1}$, or about $2.5 \%$, at the terminus. Although smaller in absolute magnitude, the diurnal signal 
is better defined up-glacier because there is no superimposed tidal "noise". Near the terminus, the tidal fluctuations are about twice as large as the melt-driven diurnal ones, while up-glacier the melt-driven signal is much larger than the tidal one. These diurnal speed fluctuations are driven by changes in water input from surface ablation. However, the data suggest that the delay time to this forcing is both spatially and temporally variable.

The situation on Columbia Glacier is somewhat different. Close to the terminus, Walters and Dunlap (1987) estimate that melt-driven variations in speed are approximately onethird the magnitude of tidally forced semi-diurnal variations. These authors also report a more constant delay time between speed and meltwater forcing, with a peak speed some 7-8 hours after peak insolation. However, it is difficult to directly compare this with our results because the methods used to estimate melt-forced fluctuations on the two glaciers were different, and neither was that effective.

Surface elevation also varies diurnally; the largest fluctuations (about $15 \mathrm{~cm}$ ) are again found near the terminus. These fluctuations are likely an indication that basal water storage fluctuates diurnally (Iken and others, 1983). Larger diurnal surface-elevation variations were observed after precipitation events, possibly indicating that water discharge is the limiting factor in determining diurnal fluctuations in water storage, as argued by Kamb and others (1994) on Columbia Glacier.

On 15 May (day 135) an abrupt change occurred in the timing of the response of the speed to meltwater input. No rain had fallen for 3 days, but there was a period of significant upwelling, and thus loss of stored water, at this time. There were also speed-up events at Bend and F, while the speed decreased at both C and Gate (Fig. 4a). Perhaps most notably, the largest calving event of the study interval occurred on this day (O'Neel, 2000). These events all followed the first period of strong ablation in the spring, and thus a change from winter to summer conditions in the glacier hydraulic system. An alternate explanation is that the responses were caused by the calving event, but this is unlikely, as other large calving events did not produce noticeable changes in the ice speed or in the response time to melt forcing.

\section{Low-frequency variations}

Speed-ups of 5-13\% of the mean speed at a location, lasting about 3 days, were observed after a period of heavy rainfall (day 145). The magnitude of this and other events did not always vary in direct accordance with the magnitude of the rainfall, as was also observed on Columbia Glacier (Fahnestock, 1991; Kamb and others, 1994). These authors instead found that peaks in speed were centered on peaks in water storage, as indicated by combined proxies of water input and marginal stream discharge. On both glaciers, rainfall events often lead to nearly complete removal of the tidal fluctuations during the time of speed-up (e.g. day 145 at $\mathrm{A}^{*}$ and $\mathrm{B}^{*}$ in Fig. $4 \mathrm{a}$; also Walters and Dunlap, 1987).

On LeConte Glacier, the timing of the speed-up on day 145 suggests that it was related to an increase in water storage: the velocity peak occurred between a major rain event and a period of substantial upwelling (Fig. 8). At some markers, an "extra slow-down" followed this speed-up, which also argues for a water-storage control. However, this slow-down is not observed at each marker, implying a poorly connected subglacial hydraulic system, as suggested by Fahnestock (1991). The asymmetric shape of the perturbations in surface elevation (Fig. 10) provides additional evidence for water-storage control. In some cases, the drop in elevation during an extra slow-down was larger than the original uplift, again implying water storage as control. There was also a slow-down observed on day 125. This was a result of a snowstorm on days $122-123(\sim 30 \mathrm{~cm}$ of snow) that effectively shut down meltwater production.

\section{Relation between horizontal and vertical motion}

Phase relations between horizontal and vertical motion provide additional information on the processes controlling glacier motion. If the basal water pressure were controlling basal motion, then the maximum horizontal speed should occur synchronously with maximum vertical speed (maximum $\mathrm{d} z(t) / \mathrm{d} t$; Iken and others, 1983). If, instead, peaks in horizontal speed and vertical displacement were in phase, then water storage would be directly related to basal motion (Fahnestock, 1991; Paterson, 1994).

Cross-correlation between $U_{\text {highfreq }}$ and $z_{\text {highfreq }}$ indicates that the maximum surface elevation lags the maximum speed by 3 hours, suggesting that water storage is responsible for variations in motion. However, the correlation is poor $(C=0.33)$, and inspection of the two series shows that the lag varies with time. At times the peak horizontal speed occurs after both the peak in vertical speed and that in $z$, as on day 143. We interpret these observations as indicators of mixed forcing by water pressure, water storage and tidal back pressure.

The response to fluctuations in pressure and storage over longer time-scales is also variable. Marker $G$ appears to exhibit a pressure-driven response (Figs 7 and 11), while just downstream at $\mathrm{D}$ and $\mathrm{F}$ the response appears to be controlled by water storage. Closer to the terminus, B and $\mathrm{C}$ show what is likely a mixed response to both pressure and storage. Thus it appears that up-glacier, where basal motion is reduced, basal water pressure is important. Near the terminus, where basal motion is largest and reorganization of the basal drainage system should occur most frequently, there is a combination of these two forcing terms, plus tidally induced changes in longitudinal stress gradients. This is likely related to the transfer of the dominant resistive stresses to the margins close to the terminus.

\section{Seasonal variations}

Seasonal variations in speed have been observed near the terminus of Columbia Glacier by Krimmel and Vaughn (1987) and Krimmel (1997). They report a maximum speed in early spring and a minimum in early fall, with a difference between maximum and minimum speed of about $2.5 \mathrm{md}^{-1}$ at a location where the mean speed is $10-15 \mathrm{~m} \mathrm{~d}^{-1}$. If we assume that the relative magnitude of seasonal change is of the same order on LeConte Glacier, then we would expect to see a decrease of about $5 \mathrm{~m} \mathrm{~d}^{-1}$ from early May to the end of August in our measured velocity. However, no such variation was observed (Table 1; Fig. 6). Nor do we expect any significant variations at other times of year, as surface water forcing is minimal or non-existent in winter. The missing seasonal variations in speed, plus the continuous rapid flow, indicate that basal motion must be significant year-round, even in the absence of surface water input. Echelmeyer and Harrison (1990) also found this to be the case on Jakobshavn Isbræ. They suggested that the rapid basal motion of that glacier would 
provide a self-sustaining quantity of basal melt from the heat produced at the bed, $q_{\mathrm{bed}}=U_{\mathrm{bed}} \tau_{\mathrm{b}}$. In the terminus region of LeConte Glacier, a maximal estimate of the melt rate due to potential energy loss can be obtained from the driving stress of $2-2.5 \mathrm{kPa}$ and a speed of $20 \mathrm{~m} \mathrm{~d}^{-1}$; this gives $1.5 \mathrm{~cm} \mathrm{~d}^{-1}$ of melt. This would be available for rapid basal motion, regardless of the season. However, the same ideas do not seem to apply to the observed seasonal speed variation on Columbia Glacier, where basal melt rates are also relatively large.

\section{CONCLUSIONS}

Our measurements on the lower $7 \mathrm{~km}$ of LeConte Glacier indicate that the velocity and surface elevation in the terminus region fluctuate at semi-diurnal and diurnal time-scales. There are also variations at longer time-scales, but there appear to be no seasonal changes. The relationship between these fluctuations gives some understanding of the mechanisms controlling the motion of this tidewater glacier. We find that:

Glose to the terminus, an out-of-phase relationship exists between the tide and horizontal ice speed, such that maximum tide corresponds to minimum speed. This is a result of changing longitudinal stress gradients superimposed on the dominant marginal drag.

At the terminus, the amplitude of diurnal variations in speed is about half as large as the semi-diurnal variations. However, the relative magnitude of these fluctuations increases up-glacier, as the tidal signal is attenuated. These diurnal variations are caused by fluctuations in surface meltwater input.

The vertical velocity of ice near the terminus varies in phase with the tide. The up-glacier decay of these vertical velocity variations indicates that the lower $300 \mathrm{~m}$ of the glacier is near flotation. Upstream of this, the glacier undergoes small diurnal uplift in response to surface meltwater input.

Precipitation events cause variations in speed that are 5 $15 \%$ of the mean speed. Abrupt increases in surface water input cause changes in basal water storage and pressure, but the relative importance of these two mechanisms in enhancing basal motion varies in both time and space. No direct relation exists between the magnitude of the precipitation and the resulting change in speed, indicating that the response depends on the state of the basal hydraulic system prior to the input event.

No seasonal changes in speed exist on the lower $7 \mathrm{~km}$ of the glacier. This is possibly related to large basal melt rates, which provide a continuous source of basal water.

These velocity variations help illuminate the important flow mechanisms in a region where large strain rates and severe crevassing make englacial and subglacial observation unfeasible. Knowledge of these velocity variations is also important in understanding the mechanisms of iceberg calving, and thus the stability of temperate tidewater glaciers.

\section{AGKNOWLEDGEMENTS}

We would like to thank P. Bowen (Petersburg High School) and C. Connor (University of Alaska Southeast) for their involvement in the initial stages of the project. B. Hitchcock, S. Seifert and P. DelVecchio provided invaluable field assistance, as did Temsco Helicopters from Petersburg. Thanks to W. D. Harrison, C. R. Warren, J. W. Glen and an anonymous reviewer for their helpful comments. This research was supported by U.S. National Science Foundation grant OPP 9877057.

\section{REFERENGES}

Alley, R. B. 1991. Sedimentary processes may cause fluctuations of tidewater glaciers. Ann. Glaciol., 15, 119-124.

Echelmeyer, K. A. 1983. Response of Blue Glacier to a perturbation in ice thickness: theory and observations. (Ph.D. thesis, California Institute of Technology, Pasadena, CA.)

Echelmeyer, K. and W. D. Harrison. 1990. Jakobshavns Isbræ, West Greenland: seasonal variations in velocity - or lack thereof. f. Glaciol., 36(122), 82-88.

Echelmeyer, K. and B. Kamb. 1987. Glacier flow in a curving channel. f. Glaciol., 33(115), 281-292. (Erratum: 35(119), 1989, p. 154.)

Fahnestock, M. A. 1991. Hydrologic control of sliding velocity in two Alaskan glaciers: observation and theory. (Ph.D. thesis, California Institute of Technology, Pasadena, CA.

Foreman, M. G. G. 1993. Manual for tidal heights analysis and prediction. Revised edition. Patricia Bay, Victoria, B.C., Department of the Environment. Institute of Ocean Sciences. (Pacific Marine Science Report 77-10.)

Godin, G. 1972. The analysis of tides. Toronto, Ont., University of Toronto Press.

Hunter, L. E., R. D. Powell and D. E. Lawson. 1996. Flux of debris transported by ice at three Alaskan tidewater glaciers. f. Glaciol., 42(140), $123-135$.

Iken, A., H. Röthlisberger, A. Flotron and W. Haeberli. 1983. The uplift of Unteraargletscher at the beginning of the melt season - a consequence of water storage at the bed? F. Glaciol., 29(101), 28-47.

Kamb, B. and K. A. Echelmeyer. 1986. Stress-gradient coupling in glacier flow: I. Longitudinal averaging of the influence of ice thickness and surface slope. F. Glaciol., 32(111), 267-284.

Kamb, B., H. Engelhardt, M. A. Fahnestock, N. Humphrey, M. Meier and D. Stone. 1994. Mechanical and hydrologic basis for the rapid motion of a large tidewater glacier. 2. Interpretation. 7. Geophys. Res., 99(B8), $15,231-15,244$.

Krimmel, R. M. 1997. Documentation of the retreat of Columbia Glacier, Alaska. Byrd Polar Res. Cent. Rep. 15, 105-108.

Krimmel, R. M. and B. H. Vaughn. 1987. Columbia Glacier, Alaska: changes in velocity 1977-1986. F. Geophys. Res., 92(B9), 8961-8968.

Meier, M. F. and A. Post. 1987. Fast tidewater glaciers. 7. Geophys. Res., 92(B9), 9051-9058.

Meier, M. and 9 others. 1994. Mechanical and hydrologic basis for the rapid motion of a large tidewater glacier. 1. Observations. 7. Geophys. Res., 99 (B8), 15,219-15,229.

Mercer, J. H. 1961. The response of fjord glaciers to changes in the firn limit. f. Glaciol., 3 (29), 850-858.

Motyka, R. J. and J. E. Begét. 1996. Taku Glacier, southeast Alaska, U.S.A.: Late Holocene history of a tidewater glacier. Arct. Alp. Res., 28(1), 42-51.

O'Neel, S. 2000. Short-term flow and calving dynamics of LeConte Glacier, Alaska. (M.Sc. thesis, University of Alaska Fairbanks.)

Paterson, W. S. B. 1994. The physics of glaciers. Third edition. Oxford, etc., Elsevier.

Post, A. and R. J. Motyka. 1995. Taku and LeConte Glaciers, Alaska: calvingspeed control of Late-Holocene asynchronous advances and retreats. Phys. Geogr., 16(1), 59-82.

Van der Veen, C. J. 1996. Tidewater calving. F. Glaciol., 42(141), 375-385.

Venteris, E. R., I. M. Whillans and C. J. van der Veen. 1997. Effect of extension rate on terminus position, Columbia Glacier, Alaska, U.S.A. Ann. Glaciol., 24, 49-53.

Walters, R. A. 1989. Small-amplitude, short-period variations in the speed of a tide-water glacier in south-central Alaska, U.S.A. Ann. Glaciol., 12, 187-191.

Walters, R. A. and W.W. Dunlap. 1987. Analysis of time series of glacier speed: Columbia Glacier, Alaska. 7. Geophys. Res., 92(B9), 8969-8975.

Warren, C. R., N. F. Glasser, S. Harrison, V. Winchester, A. R. Kerr and A. Rivera. 1995. Characteristics of tide-water calving at Glaciar San Rafael, Chile. F. Glaciol., 41 (138), 273-289. (Erratum: 41(139), p. 281.)

Zettler, B. D. and W. H. Munk. 1975. The optimum wiggliness of tidal admittances. 7. Mar. Res., 33, Supplement, 1-13. 